\title{
Spirituality and belief: Implications for study and practice of Christian spirituality
}

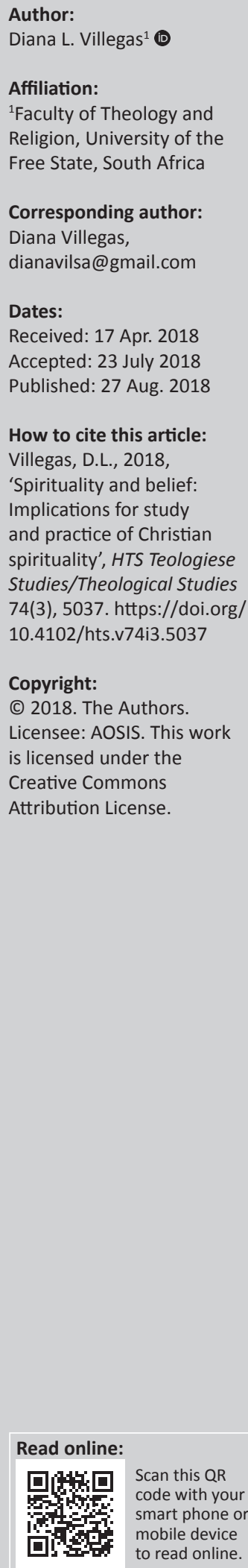

\begin{abstract}
The aim of this article is to show the inherent connection between spirituality and belief and the significance of this for the study and practice of Christian spirituality. John Hick, a scholar of religion, argues that religions arose in human culture in order to offer beliefs and practices that respond to the human quest for meaning and transcendence. Assuming spirituality refers to consciously living life in terms of such beliefs and rituals, then religion's function in culture is to provide a spirituality. Based on the latter theory, I argue for the importance of theological or confessional reflection regarding contemporary belief, given that theology reflects on the beliefs of a religion and at its best helps persons understand and integrate their beliefs into the living of life at a particular historical-cultural moment. In our contemporary globalised, pluralistic culture the influence on spiritual practice of multiple sources of wisdom is common, as shown by sociological studies discussed in this study. This cultural context calls for identification, understanding and interpretation of the beliefs of Christians, as well as study regarding how these beliefs fulfil the purpose of religion in human culture, namely offering ways of living with suffering, evil and questions about the meaning of life. I argue such study fulfils both practical and theoretical functions.
\end{abstract}

\section{Introduction}

In this study, I emphasise that beliefs are always inherent in lived spirituality. According to John Hick (1989), a scholar of religion, offering beliefs that address human questions about dealing with the limitations and sufferings of life as well as the human quest for meaning is a central function of religion in human culture. Based on this theory, I explore the importance of studying how religious beliefs are received and appropriated, particularly in our globalised, pluralistic culture where there is a smorgasbord of beliefs.

This article is written from the perspective of the contemporary discipline of Christian spirituality ${ }^{1}$ which is considered an interdisciplinary endeavour. While adhering to this point of view (this study is itself interdisciplinary), I argue here for the importance of theological reflection regarding beliefs undergirding the spiritual journeys of Christians. Theology studies beliefs from the perspective of a religious denomination's self-understanding, that is, a confessional standpoint. ${ }^{2}$ Precisely in our globalised culture, exploring, understanding and developing that self-understanding in terms of living the beliefs of a particular denomination is an important theoretical and practical task. Theology that helps interpret and understand lived spirituality must take into account contemporary cultural and historical contexts as enculturated theological reflection has a significant interpretive function in the study of Christian spirituality.

This study makes a contribution by exploring the significance of religious belief for contemporary spirituality even as there is a cultural movement towards separating spirituality and religion. The methodology is innovative in that, rather than philosophical or historical arguments, I use theories from the study of religion, sociological studies including one by a theologian, biography and theology to make an argument regarding theological reflection on belief in the field of Christian spirituality.

\section{Religion and belief: The case from the study of religion ${ }^{3}$}

John Hick, a major scholar of religion and comparative theology, developed a detailed theory about the emergence of religion in human culture and about a pattern of belief in major world religions.

\footnotetext{
1.When referencing Christian spirituality, this study presupposes a plurality of interpretations of Christianity ranging from those of different denominations to the many specific forms of Christian spirituality within denominations, such as Orthodox spirituality, Carmelite spirituality or contemplative spirituality.

2.Confession or confessional refers to perspectives from the self-understanding of a religion as opposed to beliefs viewed or studied from a non-religious perspective.
} 
As we shall see, the living of these beliefs is the spirituality of religion. Based on historical-cultural study, Hick asserts that the main world religions arose in ancient times when humans developed an awareness of their separateness from the environment and developed less communal forms of consciousness. In this period of cultural evolution, there arose religious experiences (revelation) that provided answers to questions humans had asked themselves as far back as human culture has been studied, namely questions about meaning, about suffering, and about ultimate reality (Hick 1989:3-5). What is our relationship to the cosmos? How do we understand and deal with death? Is there a purpose to life, and if so, what is it? How do we understand and live with suffering and evil? Or, as similarly formulated by Robert Cummings Neville, a scholar of comparative theology and religion, the questions religions address include the following: How are fundamental issues of the human condition to be understood? How are persons to live with affective and self-definitional issues prompted by limited situations of life? What are the ultimate sources of obligations and, therefore, what is the character of ultimate obligations and how are these to be lived? What is our place in the cosmos and how are we to relate to the cosmos? (Neville 1996:137) The answers to these questions became the beliefs and values of a religion.

Thus, as phenomena in human culture, religions offered practical answers and rituals meant to guide life. In the main world religions, these answers came about as experiences of revelation, which were eventually transmitted as beliefs; from the latter evolved rituals and practices to help live and integrate such beliefs. Beliefs, whether religious or not, guide practices intended to offer greater wholeness and/or transcendence. Sociologists tell us, 'in the social sciences, theorists write that practice ... [is] a way of understanding how beliefs and assumptions influence ordinary life' (Wuthnow 1998:170).

Hick's historical-cultural study concludes that the answers of the main world religions have a central belief and a common ideal for life's journey. There is belief in a transcendent other, 'unity-of-reality-and-value that is thought of as God, Brahman, the Dharma, Sunyata or the Tao'; and the path to a meaningful life journey with growth towards greater wholeness involves 'the sudden or gradual change of the individual from an absorbing self-concern to a new centering in the supposed unity-of-reality-and-value' (Hick 1989:36). That is, the centre out of which someone lives evolves from a selfish focus to one that embraces and cares about ultimate reality. ${ }^{4}$ The key belief here is that this transformation is made possible through the mediation of a transcendent reality, and following this transcendent reality involves a set of practices and ways of living life which give meaning and offer a path to wholeness.

The implication of Hick's analysis is that if humans seek answers to ultimate questions, there is a depth of motivation to live out the answers, that is, to weave beliefs into an intentional life project. Consciously choosing to engage in a life journey that seeks out and integrates beliefs related to meaning and transformation is congruent with the understanding of spirituality, both according to the definition most widely accepted in the discipline of Christian spirituality and according to my version of this definition which emphasises the relationship of spirituality and belief. The most accepted definition in the aforementioned discipline asserts that spirituality has to do with consciously integrating life towards self-transcendence based on one's most significant values. ${ }^{5}$ My definition states that spirituality involves purposeful approaches to the living of life guided by beliefs deemed to address questions of meaning and to make possible greater wholeness and transcendence. ${ }^{6}$ In the case of Christian spirituality, the central beliefs are in the Triune God, the possibility of relationship with this God, and in the meaning and transformation made possible through the grace to follow and imitate Jesus. ${ }^{7}$ Given the foregoing definitions, we can see that the purpose of religions in human culture (according to Hick's theory) coincides with contemporary understandings of spirituality. Accordingly, one could say that in terms of its original function in human culture, a central purpose of religion is to offer spirituality. As religions have evolved and become human institutions, they have not always functioned in this way. ${ }^{8}$ We shall return to this later in this study.

\section{Belief and the case of SBNRs (those self-referenced as 'spiritual but not religious')}

Mercadante, an ordained Presbyterian and theology professor, used sociological methodology to explore the experience of SBNRs (Mercadante 2014). She concludes that such persons, while rejecting the beliefs of organised religion, develop their own sets of beliefs. Their quest most often involves seeking answers to the same questions that led to the development of religions, and their spirituality is an expression of the answers they find.

She used an open-ended, unstructured interview technique to facilitate the emergence of themes important to interviewees rather than narrowing possible perspectives through questions that were too structured. She categorised the convictions of her interviewees into beliefs about transcendence, human nature, community and afterlife. ${ }^{9}$ In other words, the clusters of beliefs Mercadante found ultimately dealt with answers to the sort of questions about life that Hick had identified as delimiting religion as a

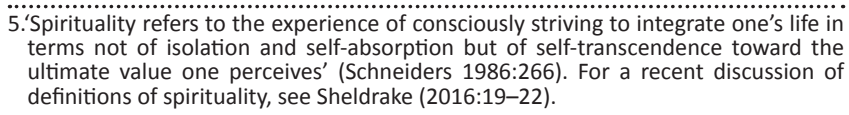
terms not of isolation and self-absorption but of self-transcendence toward the
ultimate value one perceives' (Schneiders 1986:266). For a recent discussion of ultimate value one perceives' (Schneiders 1986:266).
definitions of spirituality, see Sheldrake (2016:19-22).

6.I first proposed a version of this definition in Villegas (2012:68-70).

7.For instance, K. Waaijman, a major European voice regarding the study of spirituality, has defined Christian spirituality in terms of this central belief. Spirituality, he argues, studies 'the divine-human relational process (material object) considered from the viewpoint of transformation (formal object)' (Waaijman 2002:6).

8.This historical-cultural understanding of religion can contrast with some contemporary perspectives about religion (see Sheldrake 2016:16-18).

9.Mercadante's methodology was qualitative and searched for emerging themes and concepts from among 90 interviews and data from two focus groups (Mercadante 2014:285). For a detailed description of methodology, see Mercadante (2014:281-289) 
phenomenon of human culture. This was the case despite the fact that most of her sample rejected organised religion:

The majority insisted their ideal group would have: no dogma, no written tenets, no labels, no belief systems, no symbols, no pressure, no fixed leadership, and would be entirely nonjudgmental. (Mercadante 2014:207)

Notwithstanding this categorical rejection of religion and its beliefs, Mercadante found most interviewees held in common certain other beliefs which helped them explain, justify and organise their alternative spirituality and practices. This happened in spite of differences in age, different spiritual journeys and different reasons for adopting the 'spiritual but not religious' label (Mercadante 2014:87-88). For example, most rejected the idea of a personal God who could intervene in one's life. Instead of the Christian belief in a God with whom one can have a relationship and who heals, guides and saves, they believed in some form of force available to offer guidance, healing and meaning. In most cases, the force is impersonal, part of the cosmos or nature, or a spiritual energy of which all are a part (e.g. see Mercadante [2014:93, $121 \mathrm{ff}$.$] ).$ Yet, no matter how much interviewees insisted this force or energy was impersonal, they reported being touched by it in caring ways. They would say such things as 'the Universe is telling you something' or 'the Universe will take care of you' (Mercadante 2014:125). This conceptualisation spanned across genders, generations and geography.

These beliefs in a universal source of wisdom were related to trust in one's personal authority and inner experience as a way of coping with questions about suffering or life's meaning. Mercadante concludes that the majority of SBNRs believed in seeking answers within, hearing wisdom oneself rather than relying on the wisdom of others. They believed that wisdom found within is truer than that communicated through an outer authority (such as a religious tradition). Many believed it would be immature to believe in a personally involved God, believing instead in taking responsibility for one's connection to the cosmic or divine energy (Mercadante 2014:118). Yet, to guide their inner listening, most sought wisdom in the beliefs of a multiplicity of alternative traditions, from psychology, to Wicca, to Buddhism (Mercadante 2014:201-207). For instance, someone raised Orthodox, who had passed through a mainline Protestant denomination, found comfort and wisdom for her life in belief in a female energy that was part of the cosmos. The main room in her home contained altars to many female deities from various traditions. She explained, 'I bring a lot of females because I think we are lacking that in our spiritual energy' (Mercadante 2014:114). Her beliefs, too, combined elements from psychology, shamanism, nature worship and other aspects of New Age philosophy. She considered herself a Druid-Celtic-Native American-Judeo Christian, meaning that she borrowed beliefs from all these traditions and made her own amalgam, tying these beliefs to the foundational belief in the authority of the inner self connected to female cosmic energy.

Mercadante concludes that the eclectic beliefs woven together individually by her interviewees were intended to address questions of meaning, as well as questions about transcendence and the meaning of the cosmos; these beliefs answered questions such as who is the self, how do I grow, is there meaning after this life and how do I deal with suffering. Mercadante (2014) argues that her interviewees engaged in 'theological' reflection to guide a spiritual path when weaving beliefs to guide their life from answers to the aforementioned questions:

Some may think that in a postmodern era that is fragmented and shorn of meta-narratives, theology is not being done. But even in this context, people try to make sense of their lives, to find some compelling reason to get up each day, endure difficulties, find joy, and live with hope. . . Against the common assumption that 'spiritual but not religious' people do not have any particular theology, we have seen that these interviewees were often thinking theologically. (p. 247)

Mercadante shows us that beliefs are involved in eclectic, non-traditional forms of spirituality whether these evoke a transcendent or non-transcendent value system. In other words, all forms of experience identified as spirituality include beliefs, whether these are explicit or implicit; and these beliefs form the framework that interprets and guides experience.

\section{Studying belief}

Having argued that belief is inherent in spirituality, I propose that studying this connection is a significant project for the discipline of Christian spirituality. The definition of a discipline creates the parameters that guide its study; accordingly, my proposed definition highlights the aforementioned link. Thus, spirituality would identify and study beliefs in terms of the way in which they guide a person's or group's journey of bringing meaning to their life and in terms of how beliefs guide a path towards greater wholeness and transcendence. There are many methodologies through which the discipline of spirituality could focus on such study. In the foundational scholarship that has guided the contemporary anglophone discipline of Christian spirituality, there has been an emphasis on the interdisciplinary study of lived experience. In this work, I wish to retrieve the importance of theological reflection for the study of belief, while acknowledging the importance of an interdisciplinary approach. Indeed, this work is itself interdisciplinary.

\section{Theological reflection}

The most significant reason for proposing studying beliefs inherent in spirituality through theological reflection has to do with the function of religion in human culture as described above by Hick. If a central function of religion in human culture is to offer beliefs that make possible the spiritual journeys of persons, then reflecting on and understanding how such beliefs are received and lived in terms of a religion's self-understanding is a significant task. Theology is the discipline that reflects on the beliefs of a religion from the point of view of that self-understanding. ${ }^{10}$ Theology examines 10. For a discussion of the study of religion from both non-confessional and theological (confessional) perspectives, see Neville (1993). 
the revelatory foundations, the assertions, symbols and practices of a particular denomination or confession in order to elaborate and interpret these in new historical contexts.

In arguing for the importance of theological reflection in the study of Christian spirituality, this article presupposes a theology that is open to and in dialogue with contemporary global culture and the many currents of thought important to this culture; such a theology can be pluralistic and interdisciplinary. In mainline Christian denominations, theology further includes many specialties; it is not a monolithic discipline. Most importantly, here theology is understood as a tool of interpretation and understanding of experience from a confessional perspective; that is, this article is based on a view of theology as interpretive and not as prescriptive. ${ }^{11}$

Furthermore, I propose that theological reflection, especially when applied to beliefs guiding a spiritual journey, ought to be understood in a similar manner to disciplines such as medicine and psychology, where theoretical studies advance knowledge at the same time that there is an expectation that such advancement of knowledge will serve a practical purpose.

The importance of the confessional study of belief that is both theoretical and practical has been argued from various perspectives. Robert Cummings Neville, theologian, philosopher, and scholar of comparative theology/religion argued in a presidential address before the American Academy of Religion that one of the tasks of the study of religion from the perspective of its self-understanding (theological study) is the formation of adherents of a particular religion as culture and historical context changes. Such updating of reflection is not merely important for the theoretical elaboration of doctrines:

Both individuals ... and religious communities need intellectual guidance and critical reflection on religiously important issues, and rightly can turn to theological studies to pursue that in disciplined ways. (Neville 1993:192)

Such guidance is particularly relevant as cultures change and persons' self-understanding changes; beliefs and rituals need to be reinterpreted so that they remain accessible in meaningful ways to the adherents of the particular religion (Neville 1993:192-193). The fact that Neville, a respected scholar of religion, argued for the practical task of theological reflection at a large international gathering of scholars of religion and theologians, makes clear the importance of practical, confessional reflection on belief.

In an address to an international theological congress in Argentina, Pope Francis reminded his audience that Vatican II sought to overcome the opposition between theology and pastoral care, between living the faith (spirituality) and formal reflection on the faith (beliefs). He urged that theology

11.For a summary of discussion in the discipline of Christian spirituality regarding the role of theology in the study of spirituality, see Villegas (2012:26-35). is vital to living the faith, to making possible belief that is enculturated and rooted in its historical place and time; indeed, for Francis, any other form of theology is a betrayal of the function of the discipline (Pope Francis 2015):

It causes the Good News to cease being new and above all good; it becomes sterile, emptied of all its creative strength, its healing and resurrecting strength. And thus the faith of people today is endangered. . . . Doctrine is not a closed system, void of the dynamic capacity to pose questions, doubts, inquiries. On the contrary, Christian doctrine has a face, a body, flesh; it's called Jesus Christ and it is his Life offered to all men and women in all places. (p. 4)

Francis challenges Argentinian theologians in a stark manner that radically makes the connection between theological reflection and belief. For Christians, the central belief is in a person, Jesus, and in all he taught regarding the meaning of life, as well as the transformation and healing he offered. Mediating this message of Life (as Francis states) to particular persons in concrete historical circumstances requires reflection on the original message. While Francis is not explicitly speaking of spirituality, he clearly states that theological reflection has the urgent practical task of reflecting on beliefs in order to make them relevant, living guides for contemporary persons.

Karl Rahner, a Roman Catholic and one of the most prolific and highly regarded systematic theologians of the second half of the twentieth century, repeated throughout his long career that a central role of theology is to help persons understand the deepest meaning of their experience. For Rahner, the central and most important task of theology is to offer interpretation and understanding of belief. ${ }^{12}$ Indeed, it was his lifelong mission to offer theological reflection that would make beliefs vital and relevant to the contemporary seeker. Rahner was particularly concerned with Christians trying to understand and live beliefs in post-World War II Europe with the cultural upheaval, secularisation and emerging pluralism that dominated this time in history.

As philosophically sophisticated as his systematic theology was, Rahner indicated that he hoped his theology was a fruit of his relationship with God (his lived spirituality) and felt compelled by that experience of God to interpret belief so that others might be led to such an encounter. Marmion, in his study of Rahner and spirituality, tells us, 'For Rahner, no crude frontiers exist between doing theology ... and the life of prayer, meditation, and commitment to people'. And then he cites a reflection by Rahner himself, 'I have experienced God himself, not human words about him. This experience is not barred to anyone. I want to communicate it to others as well as I can' (1998:44). In a personal reflection at the end of his life, Rahner explained that his Catholic Christian beliefs, interpreted through the particular spirituality of Ignatius of Loyola, were the foundation of his whole theological work.

12. Many have pointed out the connection Rahner made between theological reflection and mysticism, piety and spirituality. Here I use Declan Marmion's excellent and comprehensive study (Marmion 1998). See also Egan (1998). 
In an interview in the last years of his life, Rahner reflects on an essay he wrote where he imagines what Ignatius would say to a contemporary Jesuit. 'It [the essay] is a summary of my entire theology and what I have sought to live'..$^{13}$ Speaking of his own lived experience, that is, his spirituality, Rahner states that his beliefs are the foundation of his thought. In his case, spirituality led to reflection on belief in the form of a very sophisticated theology. In turn, it was his expectation that this theology rooted in his own belief would have practical implications for helping others to believe in a pluralistic, secular world. Rahner's views on theology and spirituality are particularly valuable in that he is acclaimed by Christian scholars of multiple denominations as a firstclass scholar and systematic thinker, thus highlighting that there need not be a contradiction between excellent scholarship and practical goals for that scholarship.

\section{Enculturated theological reflection}

Cummings', Pope Francis' and Rahner's considerations above have in common an emphasis on the significance of theological reflection that is enculturated and, therefore, dialogues seriously with historical context. All three men are convinced that for beliefs to be received in a manner that indeed touches the life journeys of believers, their articulation and transmission should be rooted in the cultural and historical ethos of a particular time and place. For cultural factors shape the way life is experienced and, therefore, the way persons formulate questions about meaning and about growth. Cultural context shapes thought and makes available resources that affect the quests of persons seeking meaning and wholeness. Accordingly, theological reflection on belief must be rooted in dialogue with cultural forces.

\section{The example of Bonhoeffer}

The story of Dietrich Bonhoeffer, a German Lutheran theologian and pastor, offers a powerful example of how beliefs and the resulting spiritual path are shaped by historical developments and cultural ethos in dialogue with particular interpretations of Christian beliefs. Bonhoeffer became a theologian and pastor at the beginning of Hitler's rise to power. He was formed in the very intellectual, theoretical theology of the Berlin University of his day, but because of his encounter with God, he turned more towards a theology rooted in lived faith and practical interpretation of biblical texts. As events related to Hitler's rise affected the Lutheran church, Bonhoeffer struggled to sort out what he believed about the relationship between church and state and how these beliefs called him to act. Similarly, he struggled to sort out how to interpret his beliefs when called upon to enlist in a war he could not support. Both issues were major struggles that involved theological reflection, together with analysis of the historical, political and ideological developments going on around him. Ultimately, his beliefs about the practice of his faith made the key difference in his choices. He was convinced that God would guide him through silent listening within, together with reflection on Scripture. ${ }^{14}$ The history of how Hitler's ideologies and their gradual implementation affected persons' lives and the institutional life of the churches needs to be grasped in order to appreciate Bonhoeffer's evolving beliefs. For his beliefs evolved as he struggled with and reflected on the developments around him. These evolving beliefs shaped the spiritual path that ultimately resulted in choices leading to his imprisonment and execution in a concentration camp. Thus, a full study of Bonhoeffer's spirituality would involve identifying and reflecting on his specifically Christian beliefs, analysing how these evolved through his experience of relationship with God, as well as his reflection in the light of belief about the cultural and historical events around him. Without analysis of the latter, one would have a very incomplete understanding of Bonhoeffer's spiritual journey.

\section{Spirituality and theological reflection}

I propose that studies in Christian spirituality that involve theological reflection can have a parallel and interrelated role to that proposed by Cummings, Pope Francis and Rahner in providing both theoretical and practical knowledge that is rooted in dialogue with culture. Starting with lived experience, spirituality would study the actual questions persons are asking about ultimate reality together with the beliefs and practices they integrate into their lives. Studies in Christian spirituality could explore questions such as the following: How do persons formulate their quests for growth and greater wholeness? How do these questions and quests intersect with Christian beliefs? Which of these beliefs do persons appropriate to guide their lives? How are they actually interpreting these beliefs? In what ways have they found that Christian beliefs do not provide answers for their quests? Reflecting theologically on the answers to these questions provides a confessional perspective which would have practical benefits as suggested by Neville, Pope Francis and Rahner. Such practical study would benefit instruction and formation of pastoral personnel; it would stimulate and guide debate within confessions regarding formulation of belief in culturally relevant narratives; and it could aid individual believers in understanding the beliefs and practices of their own traditions. In other words, such studies could contribute to the formulation and transmission of confessional beliefs in a manner that responds to contemporary quests and needs. Needless to say, such studies would also advance knowledge about contemporary Christian spirituality.

I hasten to add that while this work focuses on identifying and understanding contemporary belief from an enculturated, theological perspective, this methodology could be fruitfully applied to historical texts in Christian spirituality.

14.Eric Metaxas has written an excellent biography using journals, letters and interviews with persons who knew Bonhoeffer (Metaxas 2010). While intended as a secular biography, it details Bonhoeffer's theological formation, the development of his theological perspective and his reflection regarding the choices before him. Thi biography can be read as a document about Bonhoeffer's spiritual journey. For his struggle about the role of church and state, see Chapters 12-17 and for the struggle regarding enlisting, see Chapter 21. Another biography that includes documentation of Bonhoeffer's theological and spiritual development is Marsh (2014). 


\section{Studying contemporary experience Sociological studies}

Below I describe sociological studies documenting the beliefs of contemporary North American persons who consider themselves spiritual. I propose that studying these experiences from the perspective of the self-understanding of Christian confessions would result in advancement of knowledge and practical benefits as described above. These sociological studies provide valuable information regarding the contemporary experience of those explicitly seeking to find answers to the questions Hick and Cummings specified as vital to religious quests.

\section{Hybrid nature of belief}

A wide variety of studies have documented that a majority of contemporary North Americans who consider themselves spiritual form individualised belief narratives combining wisdom from various sources. This is the case whether practising in a mainline Christian church or identifying as SBNR. This is a significant cultural development that is a direct result of contemporary cultural developments as will be discussed below. Meredith McGuire (2008), a sociologist who has focused on studying how people live and implement their religious beliefs, summarises the hybrid nature of contemporary spiritual quests in her book length study:

The hundreds of interviews and observations on which this book is based, together with the burgeoning historical and anthropological literature on religion-as-practiced, have led me to think that extensive religious blending and within-group religious heterogeneity are the norm rather than the exception. (p. 186)

For instance, she describes the lived experience of a woman who asserted that her Roman Catholic tradition was central to her life. This person told McGuire, 'But I began to weave in understandings of a variety of different religious and ... spiritual traditions', explaining how she integrates into her spiritual journey beliefs from Native American, Jewish and Zen Buddhist traditions (2008:186). McGuire finds this example representative of the sort of religious blending she uncovered..$^{15}$ Similar findings have been documented in classical studies from the late 1990s (Roof 1993; 1999; Wuthnow 1998, 2001), in a Pew Forum study from 2009 (2009) and in Mercadante's study from 2014. ${ }^{16}$

A Pew Research Center study found that mixing of beliefs is common, as shown by reports of attendance at services of more than one religion during the same period of life (in other words, the results do not indicate a serial change in religious traditions). Twenty-eight per cent of those who attended worship services weekly and $40 \%$ of those who attended worship services monthly reported at least occasionally attending services outside their own confession (Pew Center 2009:1-2). Twenty per cent of Catholics reported attending 15.See also Roof (1993: Chs. 3-5) and Wuthnow (1998:1-18, 72-84).

16.Material from Roof, Wuthnow, the Pew Research Forum and McGuire was used in Villegas (2012:2-7) services of other religious traditions (Pew Center 2009:4). Roof cites the experience of a man identifying as a practicing Roman Catholic who attended mass weekly; however, he also frequently worshiped at the local Evangelical church where he found meaningful sermons, and for support of his journey, he attended an ecumenical prayer group in his neighbourhood (Roof 1993:245).

We already saw Mercadante's (2014) documentation of the hybrid nature of the beliefs of the SBNRs she studied. She summarises:

Rather than identifying the various strands of their thought and, even less, being aware of or concerned with potential inconsistencies - my interviewees seemed content to be in the middle of a contemporary and popular stream of thought. The SBNR ethos they imbibe [combines] . . . elements of Eastern and Western religious thought, folk religion, spiritualism, 'free-thinking', as well as popular versions of scientific and psychological theories. And this spirituality is one strongly shaped by certain American values - often derived from Western religious roots, especially mainstream Protestantism - like progressivism, egalitarianism, free choice, pragmatism, and individualism. (p. 110)

\section{Problems in reception of confessional beliefs:}

Mercadante's study is also valuable in showing another finding of some studies, namely that many contemporary seekers, even those who stay in their mainline traditions, do not find traditional beliefs sufficient for their quest; or they may not have received adequate instruction regarding the beliefs and practices of their traditions. Many of Mercadante's interviewees first sought meaning and beliefs for a spiritual journey in mainline religions but became dissatisfied. Forty-three per cent of interviewees were born before 1964 (2014:57-58); these persons had mostly been brought up participating to some extent in an established Christian church, a few in the Jewish confession. All these persons had turned away from their traditions when they progressed in a search for spiritual sustenance. Some became dissatisfied because they found the beliefs of their traditions as they understood them to lack credibility, to be unhelpful or even detrimental. Mercadante reports the stories of various persons, some who had been strong believers and practitioners of their confessions. What they had in common was finding help for their spiritual quest in non-traditional beliefs outside their confession, so that eventually their traditional beliefs became irrelevant or problematic (Mercadante 2014:94-96).

Mercadante concludes that some of her interviewees were religiously illiterate, that is, they had not learnt or had not been adequately taught the beliefs of their tradition. She discusses the concept of religious illiteracy, referring to poor knowledge of one's tradition even if one attends church (Mercadante 2014:50, also footnote 36 on that page). Results from the Pew study also show how persons have not understood even foundational beliefs of their traditions, despite active participation in worship services. For instance, Pew found that almost one-third of Roman Catholics believed in astrology, in the spiritual power of crystals and 
in reincarnation (Pew Center 2009:8). Catholic tradition discourages belief in astrology and the power of items like crystals if such belief competes with trust in the power of God's grace through Jesus. Belief in reincarnation, which essentially teaches that one returns to life multiple times in order to be purified of sin, contradicts the central Christian belief in redemption through Jesus Christ. These two beliefs put forward contrasting ways of understanding how a transcendent other (God, Hick's the Real) intervenes (or does not) in life, thus making a difference in the manner in which one makes meaning of and seeks healing from experiences of failure and wrongdoing.

Mercadante's study and the Pew documentation about belief in reincarnation (and in astrology and the power of crystals) suggest that for a significant percentage of Christians, at least in North America, the formation received in their places of worship fails to communicate the beliefs of the Christian faith in such a way that these beliefs are fully understood and/or are found attractive as a spirituality that answers the life questions discussed earlier in this article.

\section{Cultural factors}

Given the emphasis of this study on the enculturated study of belief, I offer a summary of major cultural shifts that have affected findings such as those presented above, as such factors must be considered in any enculturated study of contemporary spirituality. Major cultural shifts in global culture over the last 70 years have shaped the way persons understand and articulate their search for meaning and wholeness, as well as the way they go about seeking beliefs and practices to respond to these quests. Postmodern thought ${ }^{17}$ and globalisation have resulted in the cultural ethos that there are no normative narratives. Postmodernity has questioned the existence of absolute truth, instead considering truth as variable depending on cultural and historical context. There has been a turn to individual rights. This has led to a shift towards individualised narratives about self, and about values and the meaning of life, ${ }^{18}$ this stands in contrast to previous historical periods when such narratives would be incorporated from those offered by an authority, such as a religious tradition. The related pluralism in Western cultures has resulted in the popular ethos that a broad variety of values, ideas and opinions have equal value. Thus, a Western believer, who adheres to a mainline religion, is likely to almost unconsciously assume that besides the offerings of their church, other sources of wisdom are equally 'true' or valuable. This ethos finds fertile ground in globalisation of information which, together with communication technologies, makes a variety of opinions, values and life projects easily available without the mediation of any institution (such as a religious tradition). A plurality of sources of wisdom are easily available through the internet, social media, easily downloadable e-books, full texts on websites and so on. Thus, a practicing

17.For a discussion of the complexity of the use of this term, particularly in academic contexts, see Villegas (2012:8-12).

18.Wuthnow particularly studied the evolution in views of the self, see Wuthnow (1998:142-167). See also Mercadante (2014:92-94, 103, 250).
Christian has available life projects proposed by a multiplicity of persons, some adhering to traditional religions and others adhering to psychological life projects, or projects based on a commitment to a natural lifestyle, or projects based on a mixture of beliefs. The author of classical sociological studies of religion in North America states:

In addition to their places of worship, many Americans . . . shop for spirituality at New Age and recovery bookstores or pick up spiritual tips from films, talk shows, and news specials on television... Many people take classes that expose them to science, secular philosophy, and the teachings of world religions. Large numbers of Americans participate in self-help groups, struggle with addictions and undergo therapy. (Wuthnow 1998:2)

All of the above experiences contribute to a hybrid set of beliefs that guide the search for greater wholeness and life meaning.

These cultural shifts coincide with what one sociologist calls 'the reification of the religious' (Roof 1993:78-79). That is, as religions are passed on through human institutions, these institutions over time also focus on the human task of perpetuating the institution and can become distanced from their original purpose in human culture, namely to pass on beliefs that offer meaning and the possibility of growth and self-transcendence. Accordingly, Christian denominations only at times respond to cultural shifts by offering interpretation of the hybrid sources of wisdom such that these can be meaningfully integrated into traditional beliefs.

\section{Discussion}

The documentation by sociologists of the hybrid nature of the spirituality of many Western Christians, as well as the cultural shifts in which these trends are taking place, suggests an important area of study for Christian spirituality. Understanding this experience in terms of the function of religion in human culture would be most valuable. That is, how are questions about the meaning of life being posed today? How do hybrid beliefs offer a response to these questions? What Christian beliefs (in their many confessional expressions) do persons integrate into their lives? How are these beliefs modified or shaped by the global, pluralistic nature of information aimed at growth and transformation or at offering a meaning and purpose to life? A study of these experiences from the perspective of Christian denominations' self-understanding, which involves theological reflection, would provide advancement of knowledge as well as serve the function that Neville, Pope Francis and Rahner advocate. As Neville indicated, 'individuals ... and religious communities need intellectual guidance and critical reflection on religiously important issues' (Neville 1993:192) as culture and persons' self-understanding change. As schematically indicated above, such changes have been major since the 1950s. Thus, such studies could serve the practical purpose of making feasible the development of narratives that reach contemporary Christian seekers, or perhaps such studies can make possible formulations of Christian spirituality that also integrate some of the wisdom available 
on the global marketplace, or narratives can be constructed offering interpretations of such beliefs in ways congruent with the confession's self-understanding.

\section{Practical applications: Contemporary examples}

An example of a culturally rooted study of belief, followed by reflection on pastoral practice, is one by a practical theologian Beaudoin. He evaluates music videos, fashion and other expressions of the quest for meaning of Generation $X$ to see what beliefs or theology he found in these. In his last chapter, 'Rediscovering humility in Ministry: A spiritual challenge from Generation $X^{\prime}$, he proposes pastoral approaches to offering the beliefs and practices of the tradition in a manner that responds to the quests and cultural experience of the population he studied (Beaudoin 1998:159-174).

An example of a contemporary development in lived experience that could be fruitfully studied by scholars of Christian spirituality following the perspective outlined in this study concerns an experiment offered by a Trappist monastery in the United States. While reflecting on the dwindling vocations to their spiritual path, the monks noticed the spiritual hunger of visitors to their abbey. They recognised a hunger for solitude and silence and for learning from the beliefs of the Cistercian spirituality guiding their way of life and their approach to relationship to God. They noticed this in visitors from a multiplicity of faith traditions or even from no faith at all. As a result, they have developed programmes for participation in their life and prayer, even for extended periods of time (Hiltner 2018). While the monk's reflections are clearly not a formal study, they have led to the offer of spiritual experiences that could clarify and shape belief. A scholar of spirituality, with the right study design and due permissions, could study the questions being asked by persons who participate in the experiences the monks are offering; one could study how questions are affected by the monastic experience and/or how beliefs changed or developed.

\section{Summary}

John Hick's analysis suggests religions arose in human culture to offer beliefs and practices that provided answers to the human quest for meaning and transcendence. The tools offered by religions in terms of beliefs and rituals responded to human questions about the meaning of life and to the search to live with and overcome limitations and suffering. If spirituality refers to the journey of living life practicing such beliefs and rituals, then religion's function in culture is to provide a spirituality. This link between religion and spirituality suggests that understanding the religious or confessional perspective of beliefs is significant for the living of those beliefs. Indeed, I have shown that academic leaders, theologians and pastoral leaders in contemporary Christianity have argued for the critical importance of confessional, that is, theological reflection on belief, if the beliefs of a tradition are to be valuable to those formed by contemporary cultural developments. These cultural developments were discussed in order to show the challenge to and importance of enculturated study of spirituality from the perspective of the self-understanding of religions today.

\section{Acknowledgements Competing interests}

The author declares that she has no financial or personal relationships which may have inappropriately influenced her in writing this article.

\section{References}

Beaudoin, T., 1998, Virtual faith: The irreverent spiritual quest of generation $X$ Jossey-Bass, San Francisco, CA.

Biallowons, H., Egan, H.D. \& Imhof, P. (eds.), 1990, Faith in a wintry season: Interviews and conversations with Karl Rahner in the last years of his life, 1982-84, Crossroad, New York.

Egan, H.D., 1998, Karl Rahner: The mystic of everyday life, Crossroad, New York.

Hick, J., 1989, An interpretation of religion, Yale University, New Haven, CT.

Hiltner, S., 2018, 'The world is changing. This trappist abbey isn't. Can it last?', New York Times, March 17, 2018, viewed 22 March 2018, from https://www.nytimes. com/2018/03/17/us/trappist-monks-mepkin-abbey.html

Marmion, D., 1998, A spirituality of everyday faith: A theological investigation of the notion of spirituality in Karl Rahner, Peeters, Louvain.

Marsh, C., 2014, Strange glory: A life of Dietrich Bonhoeffer, Vintage, New York.

McGuire, M.B., 2008, Lived religion: Faith and practice in everyday life, Oxford University Press, Oxford.

Mercadante, L.A., 2014, Belief without borders: Inside the minds of the spiritual but not religious, Oxford University Press, New York.

Metaxas, E., 2010, Bonhoeffer: Pastor, martyr, prophet, spy, Thomas Nelson, Nashville, TN.

Neville, R.C., 1993, 'Religious studies and theological studies', Journal of the American Academy of Religion 61, 185-200.

Neville, R.C., 1996, 'The emergence of historical consciousness', in P.H. Van Ness (ed.) Spirituality and the secular quest, pp. 129-156, Crossroad, New York.

Pew Forum for Religion and Public Life, 2009, Eastern, new age beliefs widespread: Many Americans mix multiple faiths, viewed from http://pewforum.org/ uploadedfiles/Topics/Beliefs_and_Practices/Other_Beliefs_and_Practices/ multiplefaiths.pdf

Pope Francis, 2015, Video message of his holiness Pope Francis to participants in an international theological congress held at the Pontifical Catholic University of Argentina, viewed from https://w2.vatican.va/content/francesco/en/messages/ pont-messages/2015/documents/papa-francesco_20150903_videomessaggioteologia-buenos-aires.html

Rahner, K., 1978, Ignatius of Loyola, Collins, Cleveland, $\mathrm{OH}$.

Roof, W.C., 1993, A generation of seekers: The spiritual journeys of the baby boom generation, Harper, San Francisco, CA.

Roof, W.C., 1999, Spiritual market place: Baby boomers and the remaking of American religion, Princeton University Press, Princeton, NJ.

Schneiders, S., 1986, 'Theology and spirituality: Strangers, rivals or partners?', Horizons 13, 253-274.

Sheldrake, P.F., 2016, 'Constructing spirituality: The 'politics' of definitions and historical interpretations', Religion \& Theology 23, 15-34.

Villegas, D., 2012, The Christian path in a pluralistic world and the study of spirituality, Lexington Books, Lanham, MD.

Waaijman, K., 2002, Spirituality: Forms, foundations, methods, Peeters, Leuven.

Wuthnow, R., 1998, After heaven: Spirituality in America since the 1950's, University of California Press, Berkeley, CA.

Wuthnow, R., 2001, 'Spirituality and spiritual practice', in R.K. Fenn (ed.), The Blackwell Companion to sociology of religion, pp. 306-320, Blackwell Publishers, Oxford; Malden, Massachusetts. 